See Article page XXX.

\section{Commentary: Don't go breaking my (any) heart}

\author{
Frank A. Baciewicz, Jr, MD
}

The 1976 Elton John and Kiki Dee duet "Don't Go Breaking My Heart,"1 which was Elton John's first number one hit on both the American and British music charts, is an apt reminder when performing mitral valve replacement in patients with mitral annular calcification (MAC). MAC is defined as heavy calcification of at least the posterior annulus of the mitral valve, and often the entire annulus. Mitral valve replacement for MAC has been complicated by atrial-ventricular disruption, ventricular peroration, and significant 30-day mortality.

In the article "Surgical Implantation of BalloonExpandable Heart Valves for the Treatment of Mitral Annular Calcification," 2 Smith and colleagues described their experience with open surgical implantation of an Edwards SAPIEN S3 or XT (Edwards Lifesciences Company, Irvine, Calif) balloon-expandable valve (BEV) for severe MAC. Through a sternotomy in 13 patients or a robotic approach in 38 patients, the mid-portion of the anterior mitral leaflet was excised, and a myectomy was performed in 21 patients in whom left ventricular outflow tract a narrowing was predicted. The BEV was deployed to minimize left ventricular outflow tract obstruction, and previously placed annular guiding sutures were positioned through the valve skirt to prevent embolization and paravalvular leak. The 30-day and 1 -year mortality were $13.7 \%$ and $33.3 \%$, respectively.

The patients with MAC were considered high risk $(6.8 \%$ predicted Society of Thoracic Surgeons mortality), although, based on my experience and the literature, any mitral intervention for MAC is high risk. In addition, with $62.7 \%$, or 32 of 51 , patients having a concomitant procedure, $21.5 \%$, or 11 of 51 , having a re-do operation (previous

\footnotetext{
From the Divison of Cardiothoracic Surgery, Michael and Marian Ilitch Department of Surgery, Wayne State University School of Medicine, Detroit, Mich. Disclosures: The author reported no conflicts of interest.

The Journal policy requires editors and reviewers to disclose conflicts of interest and to decline handling or reviewing manuscripts for which they may have a conflict of interest. The editors and reviewers of this article have no conflicts of interest.

Received for publication Sept 3, 2021; revisions received Sept 3, 2021; accepted for publication Sept 7, 2021.

Address for reprints: Frank A. Baciewicz, Jr, MD, Divison of Cardiothoracic Surgery, Michael and Marian Ilitch Department of Surgery, Wayne State University School of Medicine, Harper Hospital, 3990 John R, Detroit, MI 48201 (E-mail: fbaciewi@ dmc.org).

J Thorac Cardiovasc Surg 2021;

$0022-5223 / \$ 36.00$

Copyright (C) 2021 by The American Association for Thoracic Surgery

https://doi.org/10.1016/j.jtcvs.2021.09.003
}

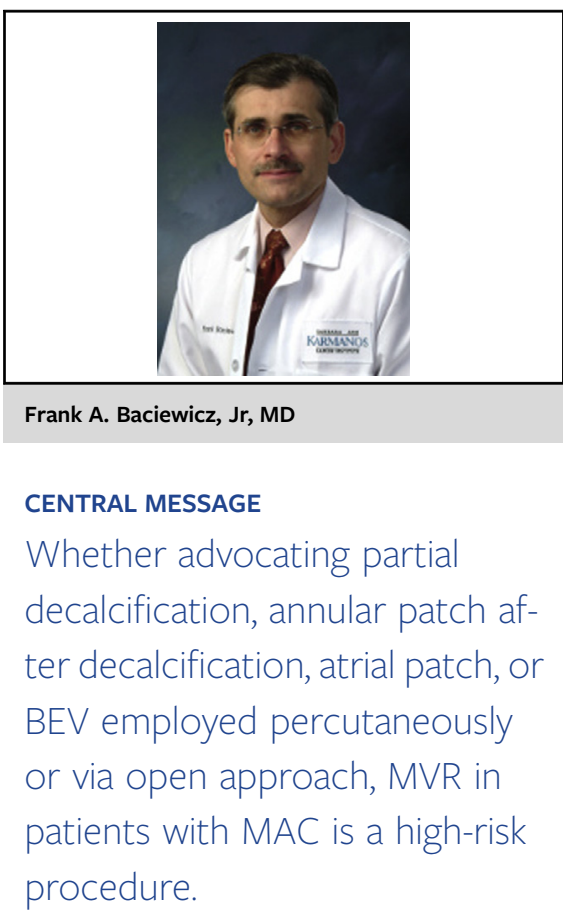

CABG), and 35 of 51 (68.6\%) being New York Heart Association class III or IV, the Society of Thoracic Surgeons predicted mortality may be understated. Many of the operated cohort might be considered inoperable.

The usual surgical techniques employed for MAC include Feindel and colleagues, ${ }^{3}$ posterior mitral annular decalcification and annular patch, which had an operative mortality of $9.3 \%$. Partial decalcification and placing valve sutures around/through calcium described by Salhiyyah and colleagues ${ }^{4}$ had an in-hospital mortality of $4.9 \%$. Nataf and colleagues ${ }^{5}$ reported placing an atrial patch and securing the prosthesis to the patch, which resulted in perioperative mortality of $23.8 \%$.

The surgical implantation of BEV was technically challenging, with a crossclamp time of $128.6 \pm 43.8$ minutes. The lengthy crossclamp time may have contributed to pulmonary edema after surgery, cardiac decompensation, and the $13.7 \%$ 30-day mortality. In addition, 1 patient had atrial-ventricular dissociation even without calcium debridement, or an annular patch. Although achieving the carefully defined technical success, patients still experienced a 33.3\% 1-year mortality.

The authors ${ }^{1}$ results are similar to surgical transatrial approach for BEV for MAC results posted by Praz and colleagues $^{6}$ and Lamelas and colleagues. ${ }^{7}$ They reported similar 30-day mortality $27.0 \%$ and $12.5 \%$, respectively. A review by Alexis and colleagues ${ }^{8}$ of all BEV techniques 
(including transapical and trans-septal) for MAC also demonstrated 20\% 30-day and 40\% 1-year mortality.

Reviewing these sobering data makes it clear that none of the aforementioned techniques-partial decalcification, total decalcification, atrial patch, BEV via surgical transatrial, or a percutaneous approach-is the superior option. If operating on MAC, one must be comfortable applying the technique that best fits that patient. I have favored partial decalcification or an atrial patch. Even when successful, one must ensure that the postoperative blood pressure is well controlled or atrial ventricular disassociation/ventricular rupture can occur after leaving the operating room.

Further experience will be necessary to define the role of $\mathrm{BEV}$ in MAC. The authors suggest that a registry of nonoperated patients to compare 30-day and long-term outcomes would be valuable, as would quality of life information on those who have survived intervention. These 2 end points might affect surgical decision making so our future surgical interventions "don't go breaking any hearts."

\section{References}

1. John Elton, Dee Kiki. (Duet). Don't Go Breaking My Heart. Los Angeles: MCA Records; 1976.

2. Smith RL, Hamandi M, Ailawadi G, George TJ, Mack MJ, DiMaio JM, et al. Surgical implantation of balloon-expandable heart valves for the treatment of mitral annular calcification. J Thorac Cardiovasc Surg. August 25, 2021 [Epub ahead of print].

3. Feindel CM, Tufail Z, David TE, Ivanov J, Armstrong S. Mitral valve surgery in patients with extensive calcification of the mitral annulus. J Thorac Cardiovasc Surg. 2003;126:777-82

4. Salhiyyah K, Kattach H, Ashoub A, Patrick D, Miskolczi S, Tsang G, et al. Mitral valve replacement in severely calcified mitral valve annulus: a 10-year-experience. Eur J Cardiothorac Surg. 2017;52:440-4.

5. Nataf P, Pavie A, Jault F, Bors V, Cabrol C, Gandjbakhch I. Intraatrial insertion of a mitral prosthesis in a destroyed or calcified mitral annulus. Ann Thorac Surg. 1994;58:163-7.

6. Praz F, Khalique OK, Lee R, Veeragandham R, Russell H, Guerrero M, et al. Transatrial implantation of a transcatheter heart valve for severe mitral annular calcification. J Thorac Cardiovasc Surg. 2018;156:132-42.

7. Lamelas J, Alnajar A. Early outcomes for surgical minimally invasive SAPIEN 3 transcatheter mitral valve replacement. Ann Thorac Surg. 2021;112: 494-500.

8. Alexis SL, Malik AH, El-Eshmawi A, George I, Sengupta A, Kodali SK, et al. Surgical and transcatheter mitral valve replacement in mitral annular calcification: a systemic review. J Am Heart Assoc. 2021;6:10. 